\title{
Symbiosis-Specific Expression of Two Medicago truncatula Nodulin Genes, MtN1 and MtN13, Encoding Products Homologous to Plant Defense Proteins
}

\author{
Pascal Gamas, Françoise de Billy, and Georges Truchet \\ Laboratoire de Biologie Moléculaire des Relations Plantes-Microorganismes, CNRS-INRA, BP 27, 31326 \\ Castanet-Tolosan Cédex, France \\ Accepted 13 January 1998.
}

Two Medicago truncatula nodulin genes putatively encoding proteins structurally related to two classes of proteins commonly associated with plant defense reactions have been characterized. MtN1 is homologous to two small, cysteine-rich, pathogen-inducible proteins from pea (pI39 and pI230), whereas MtN13 is closely related to the PR10 family of pathogenesis-related proteins. We show that neither MtN1 nor MtN13 is induced in leaves in response to pathogenic bacteria, and that both are exclusively expressed during nodulation. In situ hybridization experiments as well as Northern (RNA) studies of interactions between $M$. truncatula and either wild-type Rhizobium meliloti or mutants deficient in infection establish that MtN1 is associated with the infection process, while MtN13 represents the first specific marker described for the nodule outer cortex. Possible roles for MtN1 and MtN13 are discussed. We also present the identification of another member of the PR10 family, designated as MtPR10-1, whose regulation is strikingly different from that observed for MtN13, being constitutively expressed in roots and pathogen-inducible in leaves.

Additional keyword: gamma-thionin.

Endophytic symbioses are plant-microbe interactions in which the microorganism internally colonizes the host plant to the mutual benefit of both organisms. Rhizobia are soil bacteria that have the unique capacity to elicit on legumes the development of a novel organ, the nodule, in which they fix atmospheric dinitrogen

Nodule organogenesis takes place through a series of developmental stages. The relationship between the symbionts starts with a molecular dialogue involving activation of rhizobial nod gene expression by plant-secreted inducers and resulting in the synthesis of specific lipo-chitooligosaccharides, the Nod factors (for recent reviews see Dénarié et al. 1996; Long 1996; Schultze and Kondorosi 1996; Spaink 1996). Nod factors are able to elicit most of the morphogenetic responses that are induced by the bacteria themselves (for reviews see Hirsch 1992; Kijne 1992).

Corresponding author: Pascal Gamas; Fax: (33) 5.61.28.50.61; E-mail: gamas@toulouse.inra.fr

Nucleotide and/or amino acid sequence data are to be found at the EMBL data bank as accession nos. Y10456 (MtN1), Y10455 (MtN13), and Y08641 (MtPR10-1).
In temperate legumes such as pea or alfalfa, the bacteria penetrate the root by means of an infection thread, a tubular structure that grows inside the root hair, and down toward the nodule primordium that forms in the inner cortex. Simultaneously, a second division center develops in the middle cortex to form the nodule meristem. In alfalfa, the meristem remains active for several weeks, resulting in the development of an indeterminate nodule through which a longitudinal section reveals the entire developmental pathway along the nodule axis. Histologically, a nodule comprises central and peripheral tissues. Central tissues are subdivided into zones, from the distal meristematic zone I and passing consecutively through the prefixing zone II (infection zone), the amyloplast-rich interzone II-III, the nitrogen-fixing zone III, and finally the proximal senescent zone IV (Vasse et al. 1990). Peripheral tissues include the nodule parenchyma, nodule vascular bundles, the nodule endodermis, and the nodule cortex (Vasse et al. 1990).

Nodulation involves specific expression of certain bacterial and plant genes, as well as the coordinated differentiation of the two symbionts. Plant genes that are preferentially expressed before the onset of nitrogen fixation are designated as early nodulin genes (Van Kammen 1984) and are postulated to play a role in morphogenetic and organogenetic plant responses. Whereas the exact functions of most remain elusive, early nodulin genes have proved to be useful as molecular markers to define cell- or tissue-specific responses (for review, see Pawlowski and Bisseling 1996). By differential screening of a cDNA library made from immature Medicago truncatula root nodules, we have recently identified 29 new $M$. truncatula nodulation-related genes, termed MtN1 to MtN29 (Gamas et al. 1996). In this paper, we have characterized two of these genes, MtN1 and MtN13, that encode putative proteins structurally related to two classes of defense proteins. These genes were found to be differentially expressed during nodulation, with the expression of MtN13 being associated with the differentiation of the nodule outer cortex, whereas MtN1 expression appears to be related to infection. The possible roles of these two genes are discussed.

\section{RESULTS}

The MtN1 putative protein is homologous

to two pathogen-induced pea proteins.

Initial characterization of $M t N 1$ showed that its expression is induced approximately $48 \mathrm{~h}$ after Rhizobium meliloti in- 
oculation, and that its transcripts are abundant in Rhizobiuminduced immature root nodules. Partial sequencing of the clone did not reveal any homologies with known proteins (Gamas et al. 1996).

In this study we have completed the sequence determination of the MtN1 cDNA (Fig. 1). The longest open reading frame (ORF) covers only 222 nucleotides of the 922 nucleotides. The Southern analysis shown in Figure 2 suggests that MtN1 belongs to a small gene family, which could explain the existence of several cross-hybridizing mRNA species (Gamas et al. 1996). Data base interrogation (Table 1) revealed homologies between the MtN1 putative protein and two pea proteins, pI39 and pI230, whose corresponding mRNAs accumulate in response to the pathogen Fusarium solani (Chiang and Hadwiger 1991). A comparison of the noncoding regions did not show any similarity between the MtN1 cDNA and the two pea sequences (data not shown). The MtN1, pI39, and pI230 proteins are very similar in size $(73,72$, and 74 amino acids, respectively). A comparison of their primary sequences showed limited homologies between MtN1 and the pea proteins, as reflected by the modest statistical significance obtained with the BLASTX interrogation (Table 1). However, alignment of these proteins with programs allowing gaps to be introduced (such as gap or Multalin) revealed 67\% similarity (39\% identity) between $\mathrm{MtN} 1$ and pI230 (with three gaps), and 55\% similarity (32\% identity) between MtN1 and pI39 (with two gaps) (Fig. 3). Analysis of randomized alignments (randomizations $=100$; gap program) indicated that these similarities are statistically significant (data not shown). The two pea proteins are related to the gamma-thionins (Kragh et al. 1995), a subfamily of low-molecular-weight, cysteine-rich proteins (for a review, see Florack and Stiekema 1994). Weak homologies between MtN1 and wheat and barley gamma-thionins were detected by a BLASTX interrogation (Table 1). Alignments with gap and Multalin (Fig. 3, and data not shown) confirmed that MtN1 is more closely related to pI39 and pI230 than to sensu stricto gamma-thionins. The $\mathrm{N}$ terminus, which is strongly conserved in MtN1 and in the two pea proteins, has the features of a signal peptide, as commonly observed in thionins. The primary sequence of MtN1 downstream of the signal peptide is not very homologous to the two pea sequences, with the important exception that eight cysteine residues are found in the three proteins, at similar, but not strictly conserved, positions (Fig. 3). It is also striking that the hydrophobicity profiles are quite close for MtN1, pI39, and pI230 (Fig. 3). These observations suggest that the protein conformations are more conserved than the primary sequences. In terms of amino acid composition, it can be noted that MtN1 is more basic than pI230 and pI39 (isoelectric points of 7.79, 7.47, and 6.46, respectively, for mature proteins), and that cysteine, glycine, and basic residues are very abundant, as in pI230 and in the wheat and barley gamma-thionins.

\section{MtN13 and MtPR10-1 are two members of the PR10 family.}

Initial studies of $M t N$ clones (Gamas et al. 1996) showed that the MtN13 putative protein was homologous to DRRG49$\mathrm{C}$, a pea protein whose gene expression is induced by the pathogen F. solani (Chiang and Hadwiger 1990), and more generally to the PR10 proteins, a large family of acidic, intracellular, pathogenesis-related proteins also including different allergens such as Bet v 1 (Van Loon et al. 1994). Since then,

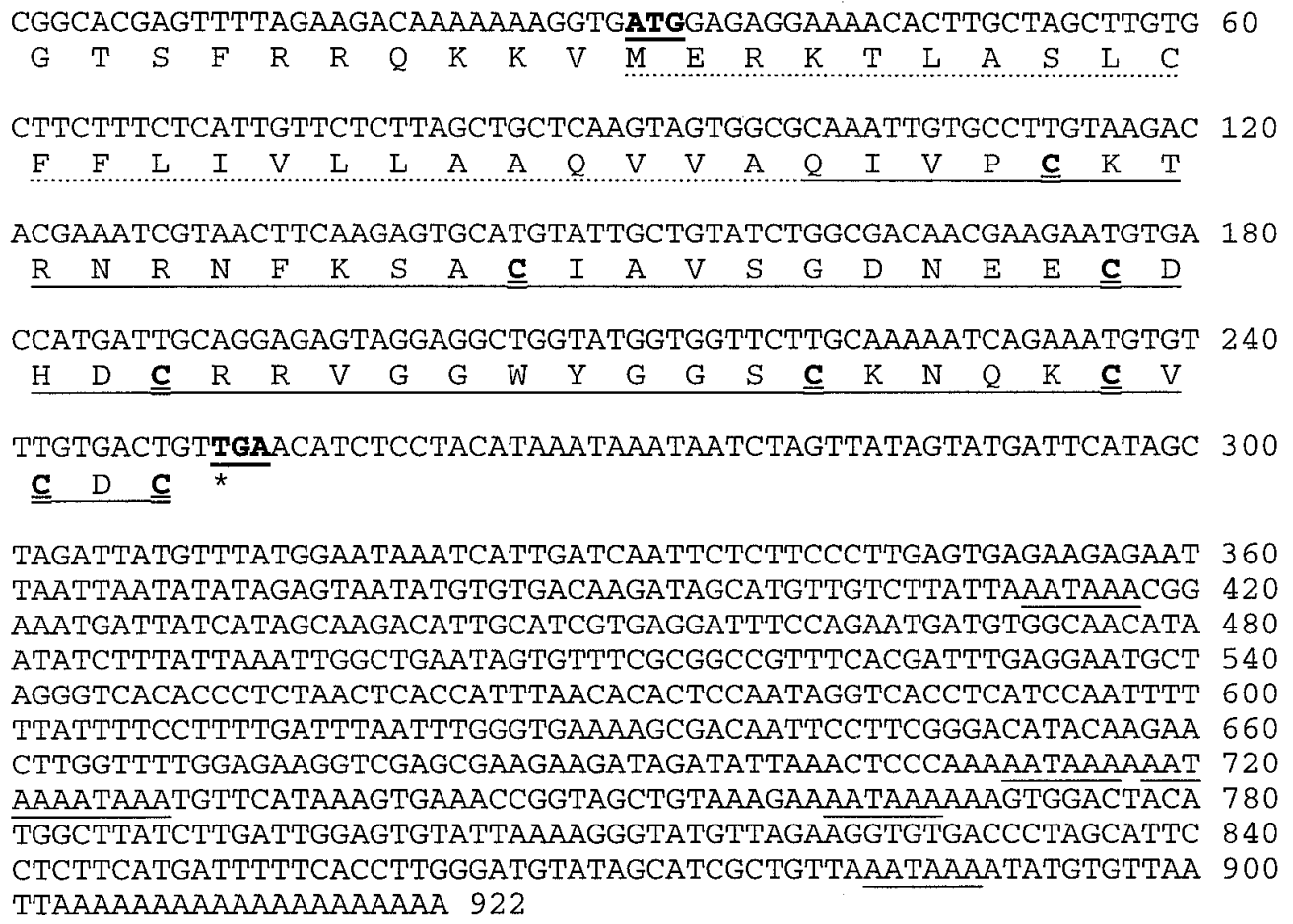

Fig. 1. cDNA and translated sequence of the MtN1 clone. Start and stop codons, as well as putative polyadenylation sites, are underlined. Longest detected putative protein sequence is underlined, showing a signal peptide (dotted line) and eight cysteine residues (bold characters, doubly underlined) in the mature protein. 
we have identified an $M$. truncatula root cDNA, picked up as a control clone not induced by $R$. meliloti, and also found to belong to the PR10 family (Table 1 ). This cDNA contained a 474-nucleotide ORF, encoding a putative protein almost identical to two M. sativa proteins, MsPR10-1 (99\% amino acid identity; Breda et al. 1996) and Srg1 (98\% amino acid identity; Truesdell and Dickman 1997). It was thus designated as MtPRI0-1.

A comparison of the DNA sequences of $M t N 13$ and MtPR10-1 showed that the conservation at the nucleotide level is very limited (data not shown), thus explaining the absence of cross-hybridization during the screening procedure. A Southern analysis of the M. truncatula genome with MtN13 and MtPR10-1 probes (Fig. 2) confirmed the absence of crosshybridization and suggested that these two genes do not belong to large, multigene families.

MtN13 and MtPR10-1 putative proteins were found to be similar in size (163 and 157 residues, respectively, with calculated molecular masses of 18.1 and $16.6 \mathrm{kDa}$ ) and charge (pI of 4.4). The PSORT program predicts that both proteins are cytoplasmic (certainty of 0.45 ). BLASTX interrogation clearly established that the MtN13 and MtPR10-1 putative proteins were homologous to the same set of PR10 proteins but with different levels of similarity (Table 1, and data not shown). A sequence alignment of MtN13 and MtPR10-1 with different members of the PR10 family showed that the overall amino-acid conservation was quite high (Fig. 4). This analysis also included two partial sequences of an $18-\mathrm{kDa}$ ribonuclease purified from ginseng calluses, found to be homologous to
PR10 proteins (Moiseyev et al. 1994). It should be noted that these RNase fragments were more homologous to MtN13 and Betula verrucosa Bet $\mathrm{v} 1 \mathrm{~J}$ than to the other PR10 proteins analyzed in Figure 4. Interestingly, the Bet $v 1$ family is a group of highly homologous proteins, including pathogeninducible proteins (Swoboda et al. 1995), which has recently been reported to exhibit RNase activity in vitro (Bufe et al. 1996; Swoboda et al. 1996).

\section{Expression of MtN1 and MtN13 during nodule development.}

In a previous study, we observed by Northern (RNA) analysis that MtN13 mRNA increased in abundance approximately 2 days later than MtN1 following inoculation by $R$. meliloti (Gamas et al. 1996). Further characterization of MtNl and MtN13 established that transcripts for these two genes were not detectable by Northern analysis in stems, leaves, flowers, or roots of noninoculated $M$. truncatula plants (Fig. 5A). In contrast, MtPR10-1 was found to be actively transcribed in roots and weakly in leaves and nodules.

To determine the tissue specificity of MtN1 and MtN13 expression during nodule development, we performed in situ hybridization on sections of developing nodules (6 days old) and nitrogen-fixing nodules ( 2 or 4 weeks old). The probes used were ${ }^{35} \mathrm{~S}$-radiolabeled, anti-sense $M t N 1$ and $M t N 13$ riboprobes. MtN1 transcripts were detected uniquely in the region of the nodule where infection threads were observed (Fig. 6AC). Thus, in developing nodules, a strong signal was seen in the central region that is almost entirely occupied, at this

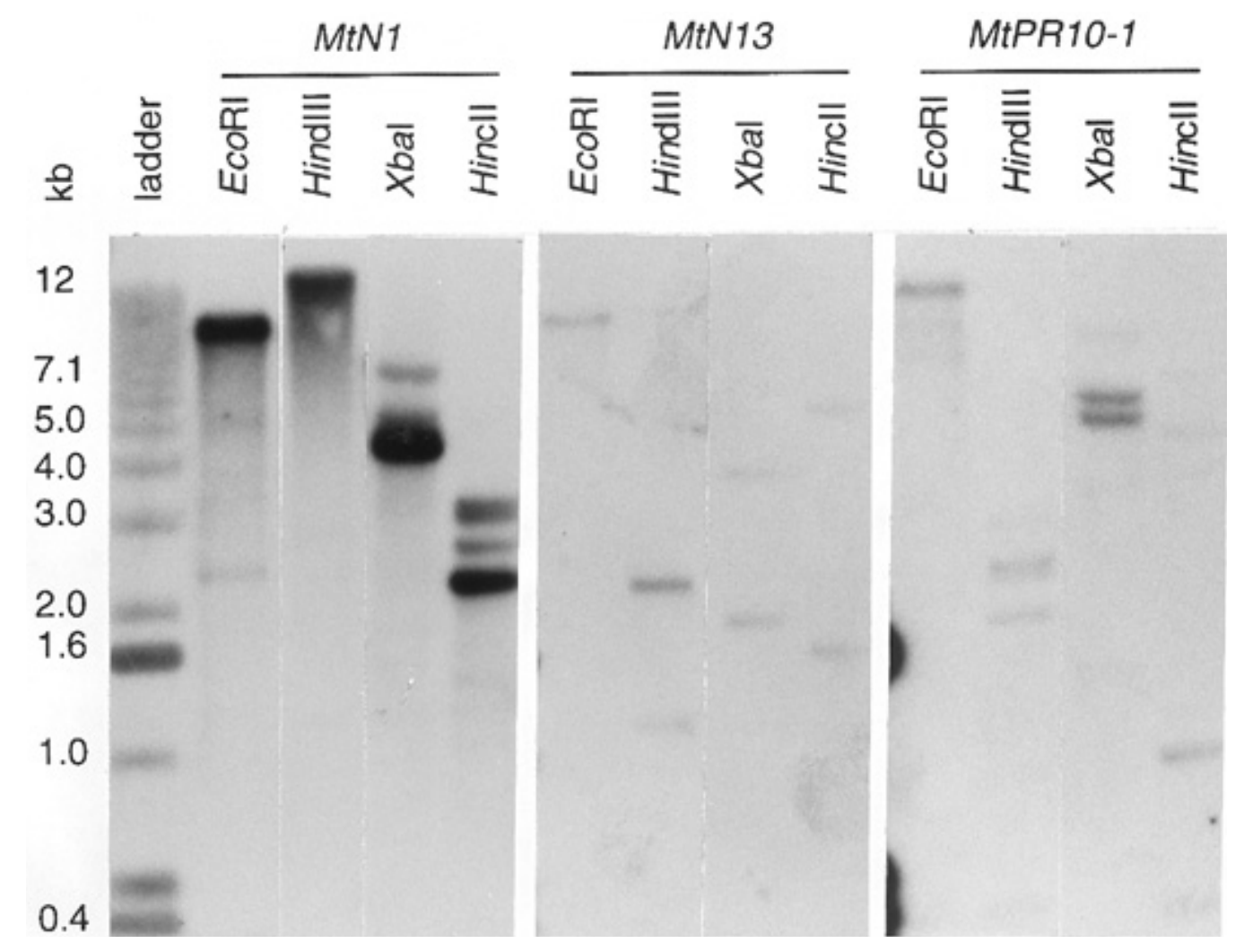

Fig. 2. Southern analysis of Medicago truncatula genomic DNA with MtN1, MtN13, and MtPR10-1 ${ }^{32} \mathrm{P}-$ labeled probes. Five micrograms of genomic DNA, hydrolyzed with the indicated restriction enzymes, was loaded per lane. Left lane shows a radiolabeled DNA size ladder (GIBCO-BRL, Life Technologies, Cergy Pontoise, France). 
stage, by an abundant network of infection threads (Fig. 6A and B). In fully differentiated mature nodules, MtN1 transcripts occurred exclusively in the distal part of prefixing zone II (Fig. 6C), a region adjacent to the meristem where infection threads develop and where rhizobia are released into the plant cytoplasm (Vasse et al 1990). There was no evidence of a reduction in gene transcription in this zone during nodule maturation, as judged by the intensity of labeling in the young and mature nodules (compare Fig. 6A and C). No signal was observed in any of the other central or the peripheral nodule tissues (Fig. 6C).

MtN13 mRNA was specifically located in the nodule cortex, the outer tissue that surrounds the entire nodule and makes the interface with the rhizosphere (Vasse et al. 1990). Transcripts were observed at an early developmental stage, i.e., when the nodule was still enclosed in the root cortex (Fig. $6 \mathrm{E}$ ) or had just emerged at the root surface (Fig. 6F). MtN13 transcription continued as the nodule matured. In nitrogenfixing nodules, the highest signal was seen in the cortical cells surrounding the apical meristem (Fig. 6G), while a significant decrease in labeling was observed in the cortex bordering the sides of the nodule (Fig. 6G). It is worth mentioning that neither MtN1 nor MtN13 transcripts were detected within axenically grown control roots, including sites of lateral root initiation (Fig. 6E and data not shown), and that the specificity of the hybridizations described above was confirmed with sense probes, which generated only low, even backgrounds for both genes (Fig. 6D and data not shown).

Table 1. Sequence homologies detected for MtN1, MtN13, and MtPRIO1 clones

\begin{tabular}{|c|c|c|}
\hline Protein & Four best homologies $^{\text {a }}$ & Probability $^{\mathbf{b}}$ \\
\hline \multirow[t]{4}{*}{$\mathrm{MtN1}$} & $\begin{array}{l}\text { Pea disease resistance response protein } 39 \\
\text { precursor (Pisum sativum) (Q01784) }\end{array}$ & $2.810^{-4}$ \\
\hline & $\begin{array}{l}\text { Pea disease resistance response protein } 230 \\
\text { precursor (Pisum sativum) (Q01783) }\end{array}$ & $1.910^{-3}$ \\
\hline & $\begin{array}{l}\text { Gamma hordothionin (Hordeum vulgare) } \\
\text { (P20230) }\end{array}$ & 0.54 \\
\hline & $\begin{array}{l}\text { Gamma-2 purothionin (Triticum turgidum) } \\
\text { (P201159) }\end{array}$ & 0.65 \\
\hline \multirow[t]{4}{*}{ MtPR10-1 } & MsPR10-1 (Medicago sativa) (X98867) & $2.910^{-105}$ \\
\hline & Srg1 (Medicago sativa) (U42752) & $1.710^{-104}$ \\
\hline & $\begin{array}{l}\text { Pea disease resistance response protein } \\
\text { DRRG49-C (Pisum sativum) (P27047) }\end{array}$ & $3.910^{-87}$ \\
\hline & $\begin{array}{l}\text { Pea disease resistance response protein } \\
\text { pI49 (Pisum sativum) (P14710) }\end{array}$ & $3.910^{-87}$ \\
\hline \multirow[t]{4}{*}{ MtN13 } & $\begin{array}{l}\text { Major allergen Cor a1 (Corylus avellana) } \\
\text { (Z72440) }\end{array}$ & $7.610^{-44 c}$ \\
\hline & $\begin{array}{l}\text { Pathogenesis-related protein (Cicer arieti- } \\
\text { num) (S47140) }\end{array}$ & $2.610^{-43}$ \\
\hline & DRRG49-C (Pisum sativum) (P27047) & $2.610^{-43}$ \\
\hline & $\begin{array}{l}\text { Major pollen allergen Bet v } 1 \text { (Betula pen- } \\
\text { dula) (P43183) }\end{array}$ & $9.210^{-43}$ \\
\hline
\end{tabular}

${ }^{a}$ Found with BLASTX interrogations (Altschul et al. 1990) of nonredundant data bases, using default parameter values.

${ }^{\mathrm{b}}$ Probability of finding the indicated homologies by chance.

${ }^{c}$ For comparison, homologies between MtN13 and pea RH2, alfalfa MsPR10-1, and $M$. truncatula MtPR10-1 putative proteins were assigned BLASTX probabilities of $1.6 \times 10^{-41}, 7.1 \times 10^{-28}$, and $6 \times$ $10^{-27}$, respectively. In addition to the proteins reported in this table, more than 100 proteins were found to have significant homologies with MtN13 and MtPR10-1 putative proteins.

\section{Expression of MtN1 and MtN13 in M. truncatula inoculated with rhizobial mutant strains or treated with Nod factors.}

Having determined the pattern of expression of MtNI and MtN13 in the wild-type interaction, we used Northern analysis to further compare the regulation of these genes in M. truncatula roots either inoculated with $R$. meliloti mutant strains or treated with Nod factors, and in $M$. sativa NAR nodules that develop in the absence of rhizobia (Truchet et al. 1989). Four mutants were used whose modified symbiotic properties have been previously described on $M$. sativa. The first two mutants, nodA and nodH, neither infect nor induce any microscopically visible response (Debellé et al. 1986; Roche et al. 1991). The third strain, a double mutant nodF/nodL, does not infect or nodulate, but elicits a strong activation of the epidermal and cortical cells (Ardourel et al. 1994). The fourth was an exoA mutant, which induces the formation of small, bacteria-free nodules with infection threads being aborted in the root hairs (Yang et al. 1992). In the time scale considered in this study these mutant strains elicited responses in $M$. truncatula similar to those described in M. sativa (data not shown).

We found that neither MtN1 nor MtN13 was expressed in roots following inoculation by the noninfective and nonnodulating $\operatorname{nod} A$, nodH, and nodF/nodL mutants (Fig. 5B). In contrast, in roots inoculated with the exoA mutant, expression of MtN13 was clearly observed, while a very low signal was detected for MtN1 on over-exposed autoradiographs (data not shown). These data are consistent with the hypothesis that expression of MtN1 and MtN13 is associated with, respectively, the infection process and the differentiation of the nodule. Moreover, these correlations were also supported by two other observations: (i) a homologue of $M t N 13$, but not of $M t N 1$, was expressed in $M$. sativa NAR nodules (Fig. 5B); and (ii) neither $M t N 13$ nor MtN1 was induced by Nod factors in M. truncatula, following $6 \mathrm{~h}$ to 15 days of treatment (data not shown; see also Gamas et al. 1996). It should be mentioned that in $M$. truncatula Nod factors are unable to elicit nodule formation although they do activate epidermal and cortical cells (data not shown; see also Gamas et al. 1996).

\section{MtN1, MtN13, and MtPR10-1 display different patterns of expression in pathogenic interactions.}

To determine whether these genes could be transcribed in response to plant pathogens, we studied their expression in leaves of M. truncatula infiltrated with Pseudomonas syringae pv. pisi or with Xanthomonas campestris pv. alfalfae, two pathogens that have been reported to induce, respectively, a hypersensitive reaction or a compatible interaction in alfalfa (Esnault et al. 1993). We first verified that M. truncatula responded to these pathogens in a manner similar to that of $M$. sativa. Visible leaf lesions appeared approximately 6 and $20 \mathrm{~h}$ after $P$. syringae and $X$. campestris infection, respectively, leading to localized necrosis with $P$. syringae and diseaselike symptoms with $X$. campestris (data not shown). A molecular marker of pathogenic interactions, the chalcone synthase CHS1 gene (Breda et al. 1996; Esnault et al. 1993), was found to be induced in $M$. truncatula in a manner similar to that in alfalfa (Fig. 5C and data not shown).

Leaf RNA analysis from two independent experiments with different inoculums revealed that MtPR10-1 was strongly induced by both pathogens, while neither MtN1 nor MtN13 ap- 
peared to be induced (Fig. 5C and data not shown). It is worth mentioning that (i) the infiltration process in itself transiently induced MtPR10-1 expression, as suggested by the analysis of water-treated leaves (Fig. 5C and data not shown), and (ii) a moderate MtPR10-1 induction was also detected in leaves after wounding (data not shown). Neither MtN1 nor MtN13 expression was observed in any of these conditions (data not shown).

\section{DISCUSSION}

In this paper, we report an analysis of three $M$. truncatula cDNA clones, MtN1, MtN13, and MtPR10-1, that putatively encode proteins showing homologies with proteins commonly associated with defense responses. Two of them, MtN1 and $M t N 13$, are expressed specifically during nodulation, while the third, MtPR10-1, is expressed in roots and in pathogenic interactions in leaves. We have been particularly interested in studying the two former genes, which encode two novel types of nodulins.

\section{Homologies between MtN1 and MtN13 and defense-related proteins.}

Data base interrogation revealed that MtN13 and MtN1 have homologies to two distinct classes of defense-related proteins in plants. The strongest homologies were found between the deduced amino-acid sequence of MtN13 and numerous members of the PR10 family, a large and ubiquitous family comprising many pathogen-induced proteins, such as MsPR10-1 in alfalfa (Breda et al. 1996) and DRRG49-C in pea (Chiang and Hadwiger 1990). The pattern of expression of $M t N 13$ appears to be quite novel for this family since MtN13 transcripts were not detected in roots or in pathogen-treated leaves, and were found to be strictly correlated with nodule development. In contrast, MtPR10-1 displayed an expression pattern similar to that observed for other $P R 10$ genes, being
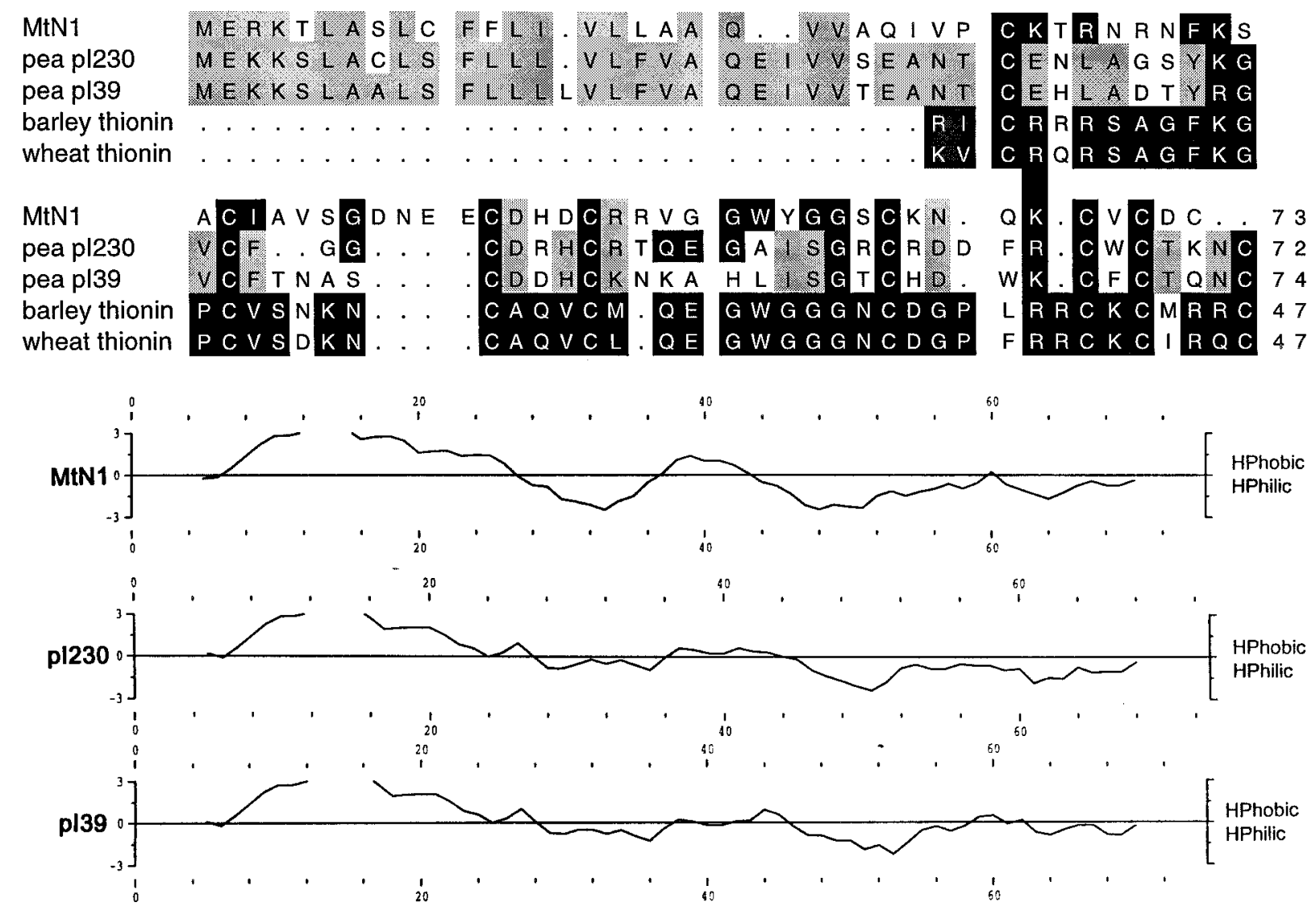

MtN1 Signal $23-X_{4}-$ Cys- $X_{10}-$ Cys- $X_{9}-$ Cys- $X_{3}-$ Cys- $X_{10}-$ Cys- $X_{4}-$ Cys- $X-C y s-X-C y s-e n d$

pl230 Signal $27-X_{2}$-Cys- $X_{10}$-Cys- $X_{3}$-Cys- $X_{3}$-Cys- $X_{10}$-Cys- $X_{5}$-Cys- $X-C y s-X_{3}$-Cys-end

pl39 Signal 28 - $X_{2}$-Cys- $X_{10}$-Cys- $X_{5}$-Cys- $X_{3}$-Cys- $X_{10}$-Cys- $X_{4}$-Cys- $X-C y s-X_{3}$-Cys-end

Fig. 3. Structure of MtN1 and related proteins. Top panel: sequence alignments between deduced sequence of MtN1 and of the two pathogen-induced preproteins pI 230 and pI39 from pea, and the protein sequence of two purified, mature gamma-thionins (barley gamma-hordothionin and wheat gamma2 purothionin). This alignment was generated with the Multalin program with default parameter values. Dark shading indicates homologies with the two gamma-thionins; light shading corresponds to homologies restricted to the pea proteins. Homologies are defined here as identities and similarities with a score equal or superior to +2 in the Multalin alignment matrix (blosom 62). Bottom panel: hydrophobicity profiles of MtN1, pI230, and pI39 preproteins, obtained with the GCG pepplot program, using the Kyte and Doolittle (1982) measure and a window of nine residues. An overall view of the primary structure of the three proteins is also presented, with an emphasis on the spacing of cysteine residues. 
pathogen-inducible in leaves and expressed in roots. Sequence alignment showed that MtPR10-1 and, to a lesser extent, MtN13 are closely related to $M$. sativa MsPR10-1 and to $P$. sativum DRRG49-C proteins. These data strongly suggest that M. truncatula MtN13 and MtPR10-1 genes are related. However, it should be emphasized that these two genes have diverged, at the DNA level, to such an extent that no crosshybridization could be detected by Northern or Southern blots. The divergence between the two genes is consistent with a scenario in which a gene duplication event has allowed independent evolution and regulation of the two sequences, one being specifically recruited for nodule development. This would be reminiscent of data showing that two non-cross-hybridizing sets of hemoglobin genes exist in soybean, one encoding the nodular leghemoglobin, and the other a hemoglobin expressed in nonsymbiotic tissues (Andersson et al. 1996).

The MtN1 putative protein does not exhibit as strong a homology with known defense-related proteins as MtN13. Nevertheless, it shares several structural features with two pea proteins, pI39 and pI230, that accumulate in response to compatible and incompatible races of the fungal pathogen $F$. solani. All three proteins are predicted to have a similar molecular weight, a signal peptide, eight cysteine residues with similar spacings, and a very similar hydrophobicity profile. Such similarities raise the possibility that MtN1 and the pea proteins pI39 and pI230 share common functional properties, although additional studies are required to assess the importance of nonconservation of many of the amino acid residues.

\section{MtN1 and MtN13 are nodulation-related genes.}

The results presented in this paper strongly suggest that the expression of $M t N 1$ and $M t N 13$ is strictly restricted to developmental events specific to root nodulation. Therefore, these genes can be considered nodulin genes (Van Kammen 1984).

$M t N 1$, which is induced significantly earlier than MtN13 (about $24 \mathrm{~h}$ after infection versus approximately 3 days for MtN13; Gamas et al. 1996), seems to be related to the infection process. Thus, mRNA is not detected in conditions in which infection does not occur (axenically grown plants, plants either inoculated with noninvasive Rhizobium mutants or treated with Nod factors, $M$. sativa NAR nodules), while a very low expression is detected in plants inoculated with the poorly invasive exoA mutant. Moreover, in the wild-type association, in situ hybridization has shown that this gene is specifically expressed in the infection part of prefixing zone II. The observation that the intensity of the signal in this zone did not vary significantly in nodules collected at different stages of development indicates that the signal decrease noticed by Northern analysis as the nodule ages (Gamas et al. 1996) is likely due to a dilution effect.

Previous studies have already resulted in the cloning and characterization of pea and alfalfa early nodulin genes that are expressed in the infection zone of the nodule, such as ENOD12 (Allison et al. 1993; Pichon et al. 1992; Scheres et al. 1990), ENOD5 (Scheres et al. 1990), and ENOD10 (Löbler and Hirsch 1993). The proteins encoded by these genes are (hydroxy)proline-rich proteins (PRPs) with an N-terminal signal peptide sequence and they are suspected to be localized in the cell wall. Our sequence data show that MtN1 is an infection-related protein structurally unrelated to this PRP family.

Several early nodulin genes have already been shown to be expressed in noninvaded peripheral or central nodule tissues, such as ENOD2 in the nodule parenchyma (Van de Wiel et al. 1990) or MtPRP4 in the nodule meristem (Wilson et al. 1994). To our knowledge, MtN13 is the first nodulin found to be specifically expressed in the outer cortex, another noninvaded tissue that surrounds developing and mature nodules (Vasse et al. 1990). MtN13 activation is observed only in situations in which nodules develop, i.e., in wild-type nodules or in nodules elicited by a noninfective exoA mutant of $R$. meliloti.

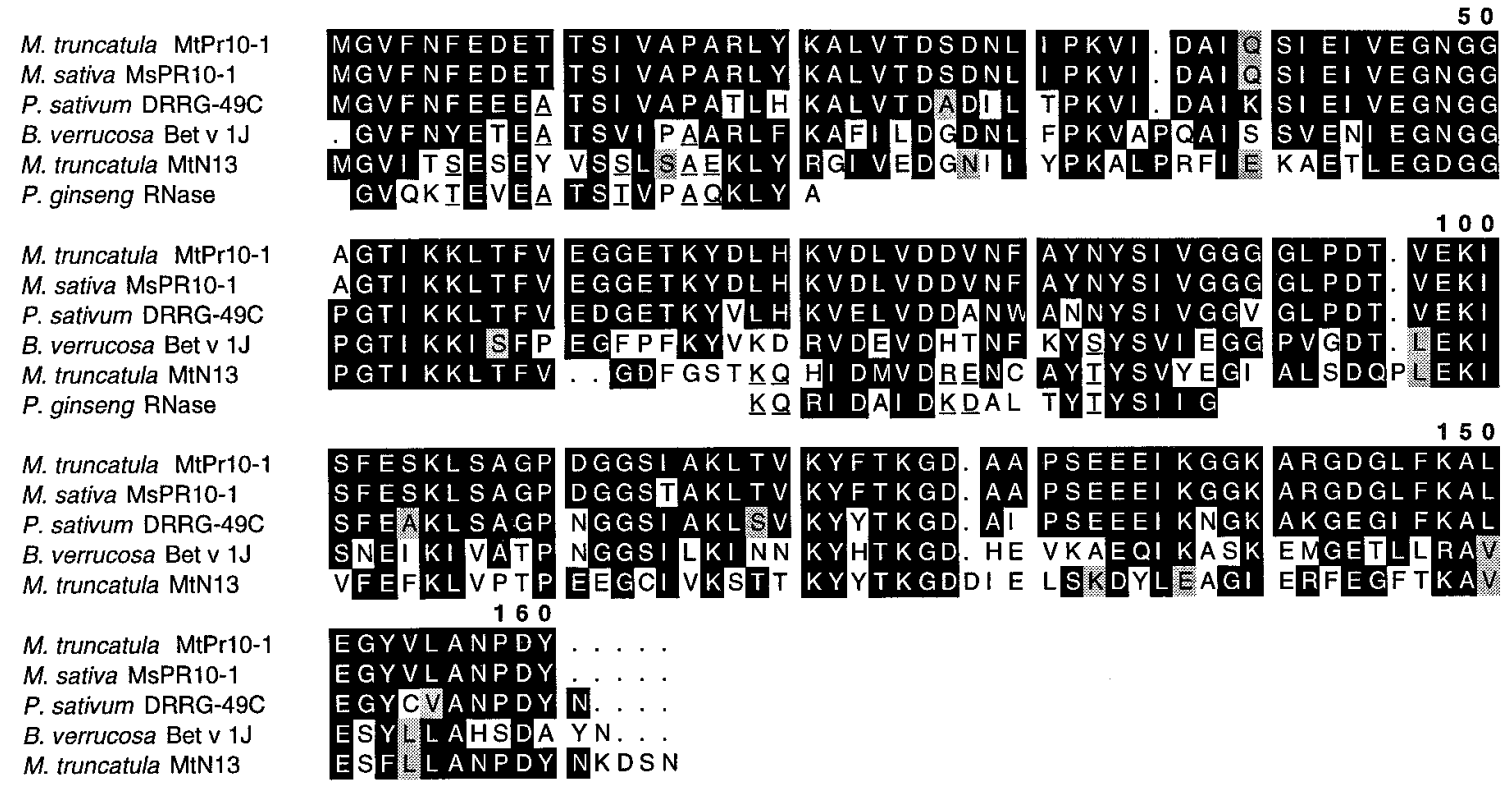

Fig. 4. Sequence alignment between MtPR10-1, MtN13, different members of PR10 family, and the partial sequence of a ginseng ribonuclease (RNase), generated with the Multalin program, using default parameter values. Dark shading indicates strong homologies, defined as identities and similarities with a score equal or superior to +2 in the Multalin alignment matrix (blosom 62). Light shading corresponds to weaker homologies, defined here as similarities with a score of +1 in the alignment matrix. Homologies specifically observed with the ginseng RNase (Moiseyev et al., 1994) are underlined. 


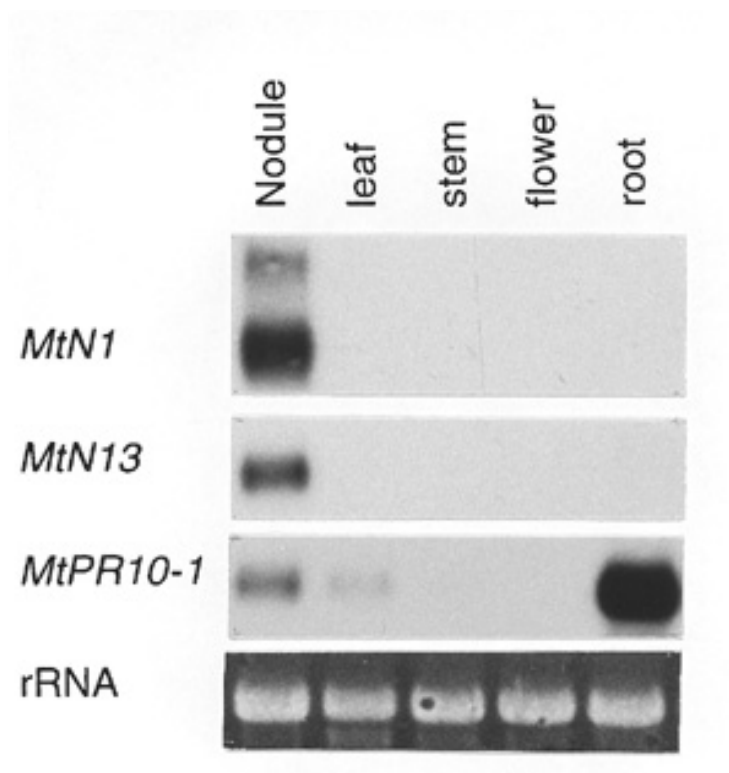

A
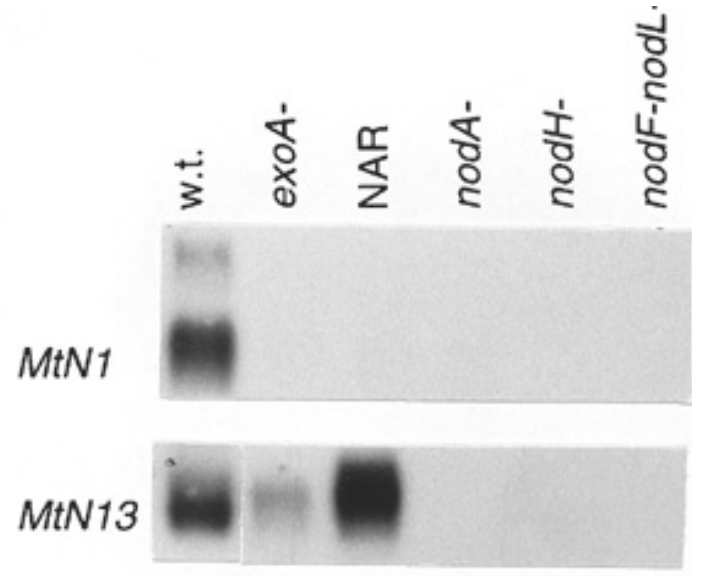

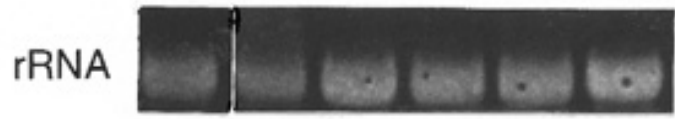
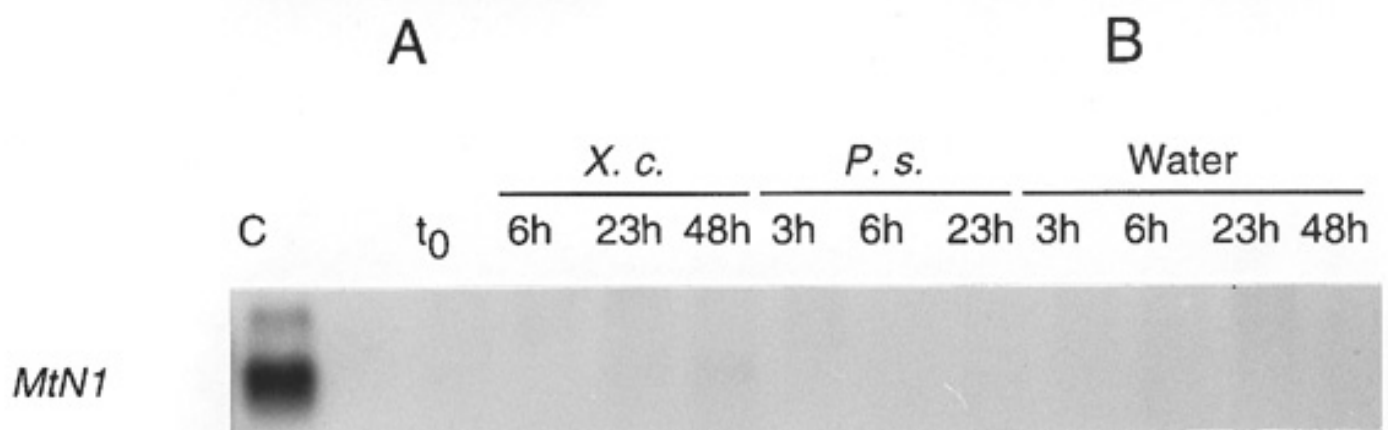

MtN13

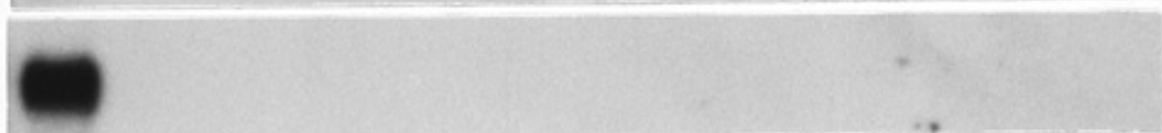

MtPR10-1

CHS1

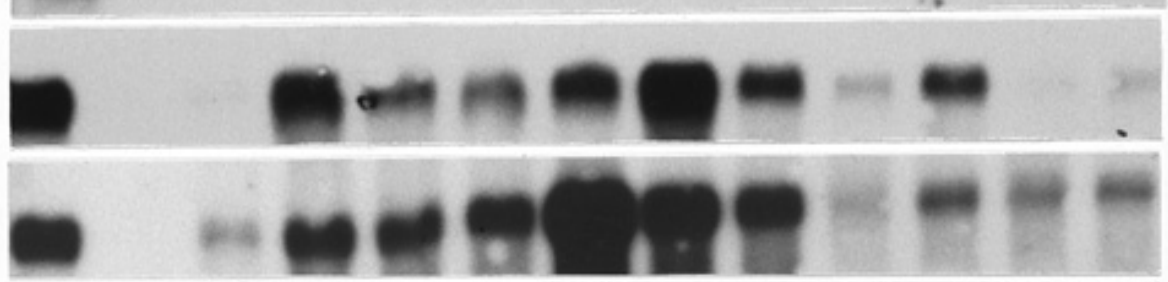

rRNA

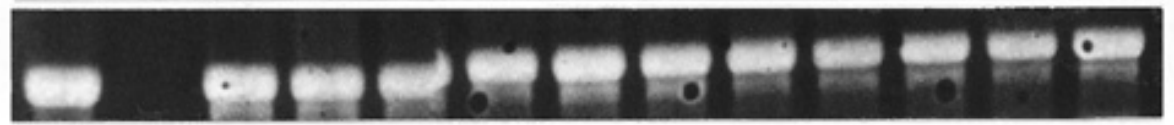

Fig. 5. Northern (RNA) analysis of Medicago truncatula total RNA. Corresponding ${ }^{32} \mathrm{P}$-radiolabeled probes are indicated on the left. Two transcripts are detected with the $M t N 1$ probe. Approximately $6 \mu \mathrm{g}$ of RNA was loaded per lane. Bottom lane shows the ethidium bromide-stained $28 \mathrm{~S}$ rRNA band, after transfer of total RNA onto the blotting membrane. A, RNA extracted from different $M$. truncatula organs. B, RNA extracted from Rhizobium-treated $M$. truncatula roots, and from isolated M. sativa spontaneous (NAR) nodules. M. truncatula RNA was isolated from whole root sytems, harvested 6 days after inoculation with wild-type (w.t.) or mutant strains of $R$. meliloti. At this time point, small, empty nodules were visible after treatment with the exoA mutant. The NAR lane corresponds to RNA extracted from isolated $M$. sativa nodules, harvested after 3 weeks of combined nitrogen starvation. When the exoA mutant and the NAR lanes are compared, it is apparent that RNA prepared from isolated nodules gives a more intense signal than RNA extracted from whole root systems. C, RNA extracted from leaves infiltrated with Xanthomonas campestris pv. alfalfae (X. c.), Pseudomonas syringae pv. pisi (P. s.), and water. Blots were hybridized with probes corresponding to MtN1, MtN13, MtPR10-1, and a chalcone synthase gene (CHS1) from M. sativa (Esnault et al. 1993). Samples were harvested at indicated time points. A previous experiment with a more detailed kinetic analysis showed that cytological symptoms and gene activation were more rapidly induced by $P$. syringae than by $X$. campestris (data not shown), in agreement with results by Esnault et al. (1993) on M. sativa. The t0 lane corresponds to a leaf sample harvested just before the beginning of the infiltration procedure. Lane C shows positive controls corresponding to nodule RNA for the MtN1 and MtN13 lanes, or to root RNA for the MtPR10-1 and CHS1 lanes. 
MtN13 transcripts are not detected in situations in which symbiotic plant responses are not elicited (inoculation with nodA and nodH mutants), or in which they are limited to root-hair or cortical-cell activation (inoculation with the nodF/nodL dou- ble mutant or treatment with wild-type Nod factors) (Ardourel et al. 1994; Gamas et al. 1996; P. Gamas, unpublished data). That a close homologue of MtN13 is expressed in spontaneous M. sativa NAR nodules (Gamas et al. 1996; this study) also
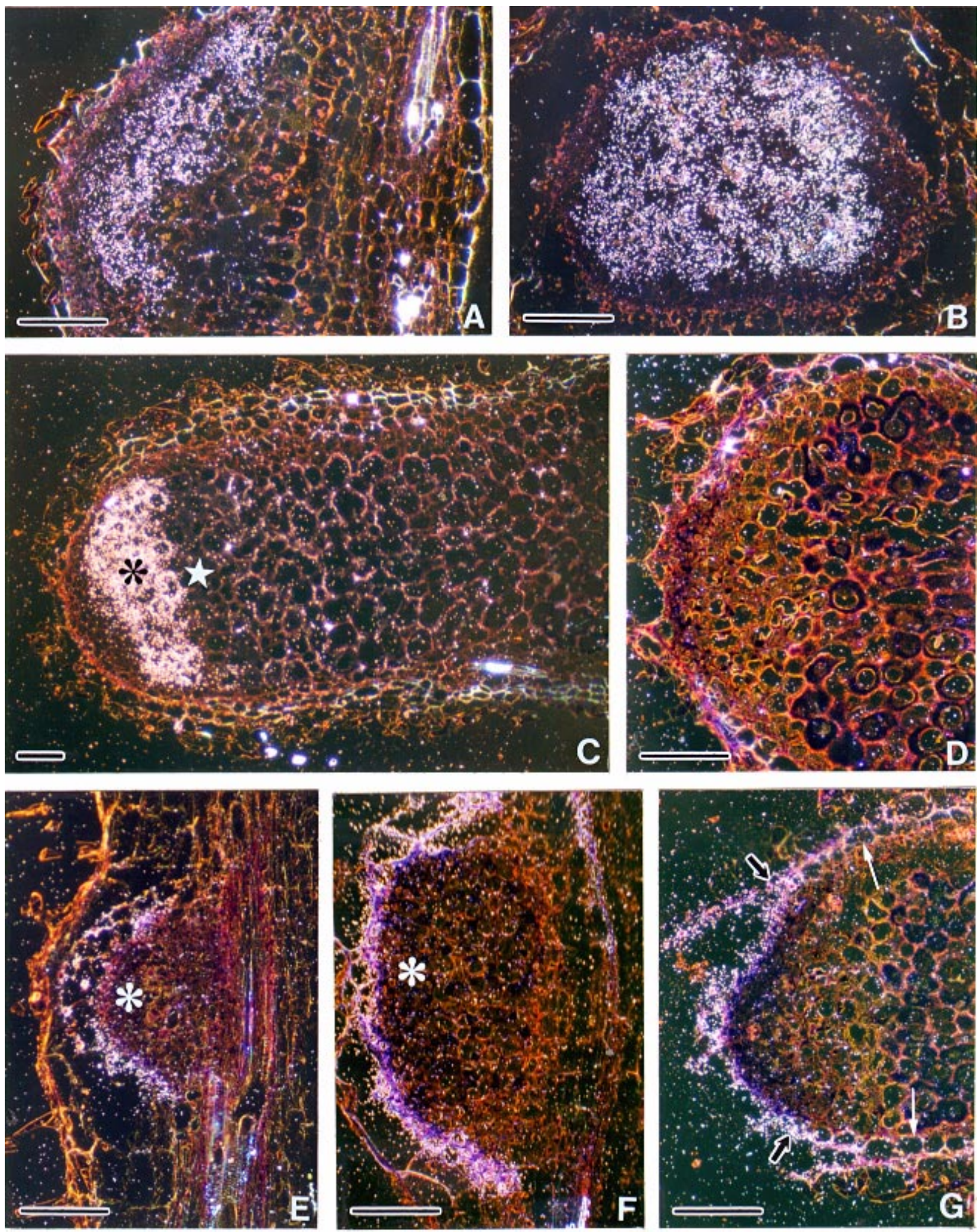
supports the conclusion that bacterial infection is not required for MtN13 induction. Moreover, our data show that MtN13 is not expressed in root tissues, including the root cortex, but requires the formation of an active nodule meristem, able to sustain an organogenetic process and tissue differentiation. This, and the fact that MtN13 is strongly expressed in the cortex of mature nodules, indicates that the nodule cortex is a genuine tissue, originating from the nodule meristem and displaying properties different from epidermal and cortical root tissues.

\section{Possible roles for MtN1 and MtN13.}

Two alternative hypotheses can be considered for the roles of MtN1 and MtN13 in the symbiosis: either they are defense proteins or they are involved in developmental processes unrelated to defense reactions.

The possibility that MtN1 and MtN13 are involved in defense mechanisms is suggested by the sequence homologies discussed above. To explain the fact that neither MtN1 nor MtN13 appear to be induced by the two bacterial pathogens tested in this study, it can be proposed that these two genes belong to a class of nodulation-specific defense genes, whose expression would be specifically triggered by Rhizobium in the same way as, for example, nodulation-specific copies of leghemoglobin genes are activated during symbiosis. Following on from this idea, it could be proposed that MtN13 is a symbiotic homologue of MtPR10-1, with both proteins having a similar function, one in response to Rhizobium and the other in response to pathogens.

If such specific defense proteins are expressed during nodulation, it is interesting to envisage their possible functions. One possibility is that they could play a protective role to prevent pathogenic infections of the root nodule, an organ representing a rich carbon source for the soil micro-flora. MtN13 could constitute a protection against pathogens present in the external medium, whereas MtN1 might be part of a mechanism preventing pathogens from taking advantage of the infection threads to invade the plant. This idea is supported by the fact that MtN13 is closely related to RH2, a pea protein specifically expressed in root epidermal cells and proposed to contribute to a constitutive defense mechanism (Mylona et al. 1994). It is also worth noting that, despite the fact that the nodular outer cortex is a loose peripheral tissue (Vasse et al. 1990), pathogenic contamination has never been described to occur in nodules developing in soil. Finally, that MtN13 exhibits substantial sequence similarities with two proteins showing a ribonuclease activity (ginseng RNase: Moiseyev et al. 1994; Bet v 1: Bufe et al. 1996; Swoboda et al. 1996) opens the possibility that MtN13 has such an RNase activity, possibly involved in mediating cytotoxic effects.

Alternatively to the hypothesis of a protective role against pathogens, it can be imagined that MtN1 represents a defense protein turned on by the infection process and possibly directed against Rhizobium itself. This speculation would be contrary to the hypothesis that efficient nodulation involves the suppression of plant defense mechanisms (see reviews by Baron and Zambriski 1995; McKhann and Hirsch 1994 ). Indeed, a clear activation of defense reactions in the symbiosis has so far been observed only in the case of late, unsuccessful infections occurring in wild-type association (Vasse et al. 1993), or in noneffective associations involving plant or Rhizobium mutants (Benaben et al. 1995; Niehaus et al. 1993; Noel et al. 1986). However, it cannot be excluded that partial defense reactions are turned on by successful wild-type $R h i$ zobium infections, which might not have been detected so far due to the lack of appropriate markers.

As mentioned earlier, MtN1 and MtN13 may alternatively play a developmental role not directly related to a defense mechanism, despite the sequence homologies found with defense proteins. Indeed, in the absence of detailed structurefunction analysis, it can be misleading to extrapolate functional similarities from structural homologies, which might simply reflect common evolutionary origins. Moreover, even if MtN1 and MtN13 are functional homologues of pathogenesis-related (PR) proteins, it should be emphasized that the actual functions of these PR proteins, during pathogenic interactions, are not known. For example, thionins, although inhibiting microbial growth, have also been proposed to be involved in signal transduction or modification of the cell wall upon infection (reviewed in Florack and Stiekema 1994). The expression of several PR proteins has already been observed in the absence of pathogens, especially during developmental processes such as flower development (Cutt and Klessig 1992; Gu et al. 1992; Lotan et al. 1989; Milligan and Gasser 1995; Neale et al. 1990). It could thus be argued that morphogenetic processes such as nodulation or flower development might require proteins also implicated in defense mechanisms. It should also be noted that several common markers of defense reactions, such as chitinases or peroxidases, are already suspected to play various roles during nodulation other than defense responses (Cook et al. 1995; De Jong et al. 1992; Staehelin et al. 1994).

It is intriguing to have identified nodulins that present homologies to defense proteins and that are expressed during early nodulation steps. To evaluate whether or not $M t N 1$ and $M t N 13$ are indeed involved in defense-reactions, we now plan to analyze the behavior of transgenic plants in which the expression of these genes is altered.

\section{MATERIAL AND METHODS}

\section{Bacterial strains.}

Xanthomonas campestris pv. alfalfae, strain \#3837, was provided by the French Collection of Phythopathogenic Bacteria

Fig. 6. In situ hybridization of Medicago truncatula nodule sections with MtN1 (A-C) and MtN13 (E-H) ${ }^{35}$ S-labeled anti-sense probes, and with MtN1 ${ }^{35}$ S-labeled sense probe (D). A, B, E, and F, 6-day-old nodules. C, D, and G, 4-week-old nodules. Dark field microscopy. A, Longitudinal section. A strong signal is seen in submeristematic region that corresponds to growing part of infection network. Bar $=100 \mu \mathrm{m}$. $\mathbf{B}$, Tranverse section through hybridizing region. A uniform pattern of hybridization is seen in the central tissue. Bar $=100 \mu \mathrm{m}$. C, Longitudinal section. Hybridization signal (asterisk) is observed exclusively at distal end of the prefixing zone II. No signal is seen in the proximal part of this zone (star). Bar = $100 \mu \mathrm{m}$. D, MtN1 sense probe. Labeling is absent. Bar $=100 \mu \mathrm{m}$. E and $\mathbf{F}$, Longitudinal sections. A uniform pattern of hybridization is observed within the nodule cortex. Nodule meristem is indicated by asterisks. No signal is observed in the root tissues. Bars $=100 \mu \mathrm{m}$. G, Longitudinal section. A significant decrease of the hybridization signal within the cortex (black arrows) is observed from top to sides of nodule. White arrows point to nodule endodermis. Bar $=100 \mu \mathrm{m}$. 
(INRA, Station de Phythobactériologie, 49070, Beaucouzé, France). Pseudomonas syringae pv. pisi was obtained from D. Roby (our laboratory). Rhizobium meliloti 1021 exoA32::Tn5 (pXLGD4) was provided by J. Leigh (Washington University, Seattle). The other Rhizobium strains were constructed by J. Dénarié's group: wild-type $R$. meliloti RCR2011 pXLGD4 (GMI 6526; Ardourel et al. 1994), R. meliloti RCR2011 nodA::Tn5 \#2208 (GMI 5382; Debellé et al. 1986), R. meliloti RCR2011 nodH::Tn5 \#2313 pXLGD4 (GMI 6527; Faucher et al. 1989), $R$. meliloti RCR2011 $\Delta($ nodF $) 13$ nodL::Tn5 pXLGD4 (GMI 6630), R. meliloti RCR2011 $\Delta($ nodF $) 13$ nodL::Tn5 pMH682 (GMI 6629; Ardourel et al. 1994). X. campestris was grown in Kado medium (Kado and Heskett 1970), P. pisi in King's B medium (King et al. 1954), and Rhizobium in TY medium (Sambrook et al. 1989) supplemented with $6 \mathrm{mM}$ calcium chloride and appropriate selective antibiotics.

\section{Plant growth and treatment conditions.}

Plants of $M$. truncatula cv. Jemalong genotype J5 (Barker et al. 1990) were grown in growth pouches, in the nitrogen-free growth medium described by Gallusci et al. (1991). Rhizobial inoculation was performed on 8-day-old plants, with exponentially growing bacteria resuspended in the plant growth medium $\left(10^{7} \mathrm{CFU} / \mathrm{ml}, 1 \mathrm{ml}\right.$ per pouch). For treatments with pathogenic bacteria, plants were grown in the same medium supplemented with $5 \mathrm{mM}$ ammonium nitrate. Leaf infiltration by $P$. syringae pv. pisi or by $X$. campestris pv. alfalfae was carried out on 2-week-old plants with bacteria from overnight cultures, pelleted by centrifugation, washed in sterile water, and resuspended in water $\left(10^{9}\right.$ and $\left.10^{8} \mathrm{CFU} / \mathrm{ml}\right)$.

\section{RNA and DNA analysis.}

Total RNA was extracted from whole root systems following the procedure of Jackson and Larkins (1976). For RNA extraction from isolated nodules, flowers, stems, and leaves, plants were grown in aeroponic conditions, as in Gamas et al. (1996). Northern and Southern analyses were conducted with Nytran Plus membranes according to the manufacturer's instructions (Schleicher \& Schuell, Dassel, Germany). Varying the wash stringency did not qualitatively affect the hybridization signals.

DNA sequencing was carried out on both strands, manually as in Gamas et al. (1996), or automatically with a PerkinElmer/ABI 373A sequencer (Foster City, CA).

\section{In situ hybridization.}

In situ hybridizations were conducted on $7-\mu \mathrm{m}$ sections, following the procedure described in de Billy et al. (1991), except that slides were exposed for 3 weeks, with Amersham LM1 emulsion (Amersham France, Les Ulis). Hybridized and exposed sections were stained with $0.02 \%$ toluidine blue for $20 \mathrm{~s}$, and finally observed by bright- or dark-field microscopy with an Olympus Vanox light microscope.

\section{Computer analysis.}

Sequence data were analyzed with the University of Wisconsin Genetic Computer Group (GCG) software (Program Manual for the Wisconsin Package, Version 8, Genetics Computer Group, Madison, WI). The following GCG programs were used: bestfit, fasta, gap, pepplot, peptidesort, prime. Predictions for protein localization were obtained with the PSORT program (Nakai and Kanehisa 1992). Homology searches in data bases by the BLASTX program were carried out through the NCBI BLAST E-mail Server. Sequence alignments were realized with the Multalin program (Corpet 1988).

\section{ACKNOWLEDGMENTS}

We are grateful to M. Arlat and L. Godiard for their advice concerning the pathogenic interaction assays, to J. Gouzy for computer assistance, and to F. Carbonne for automatic sequencing. We thank R. Esnault and C. Breda (ISV, Gif-sur-Yvette, France) for providing us with the CHS1 clone and L. Gardan (INRA Angers, France) for sending us the $X$. campestris strains. We thank very much D. Barker, P. Boistard, J. Cullimore, and F. de Carvalho-Niebel for critical reading of the manuscript, and J. Cullimore for English reviewing. We thank other members of our research groups for stimulating discussions, continuous help, and exchange of material. This work was funded in part by the European Communities' Biotech Program (no. PL920498, as part of the Project of Technological Priority 1993-1996), the Human Capital and Mobility Program (no. ERBCHRXCT940656 1994-1996) and the Training and Mobility of Researchers Program (no. FMRX-CT96-0039 1996-1999).

\section{LITERATURE CITED}

Allison, L. A., Kiss, G. B., Bauer, P., Poiret, M., Savouré, A., Kondorosi, E., and Kondorosi, A. 1993. Identification of two alfalfa early nodulin genes with homology to members of the pea Enod12 family. Plant Mol. Biol. 21:375-380.

Altschul, S. F., Gish, W., Miller, W., Myers, E. W., and Lipman, D. 1990. Basic local alignment search tool. J. Mol. Biol. 215:403-410.

Andersson, C., Ostergaard Jensen, E., Llewellyn, D., Dennis, E., and Peacock, W. J. 1996. A new hemoglobin gene from soybean: A role for hemoglobin in all plants. Proc. Natl. Acad. Sci. USA 93:5682-5687.

Ardourel, M., Demont, N., Debellé, F., Maillet, F., de Billy, F., Promé J. C., Dénarié, J., and Truchet, G. 1994. Rhizobium meliloti lipooligosaccharide nodulation factors: Different structural requirements for bacterial entry into target root hair cells and induction of plant symbiotic developmental responses. Plant Cell 6:1357-1374.

Barker, D. G., Bianchi, S., Blondon, F., Datté, Y., Duc, G., Flament, P., Gallusci, P., Génier, P., Guy, P., Muel, X., Tourneur, J., Dénarié, J., and Huguet, T. 1990. Medicago truncatula, a model plant for studying the molecular genetics of the Rhizobium-legume symbiosis. Plant Mol. Biol. Rep. 8:40-49.

Baron, C., and Zambriski, P. 1995. The plant response in pathogenesis, symbiosis, and wounding: Variations on a common theme? Annu. Rev. Genet. 29:107-129.

Benaben, V., Duc, G., Lefebvre, V., and Huguet, T. 1995. TE7, an inefficient symbiotic mutant of Medicago truncatula Gaertn. cv Jemalong. Plant Physiol. 107:53-62.

Breda, C., Sallaud, C., El-Turk, J., Buffard, D., de Kosak, I., Esnault, R., and Kondorosi, A. 1996. Defense reaction in Medicago sativa: A gene encoding a class $10 \mathrm{PR}$ protein is expressed in vascular bundles. Mol. Plant-Microbe Interact. 9:713-719.

Bufe, A., Spangfort, M. D., Kahlert, M., Schlaak, M., and Becker, W. M. 1996. The major birch pollen allergen, Bet v 1, shows ribonuclease activity. Planta 199:413-415.

Chiang, C. C., and Hadwiger, L. A. 1990. Cloning and characterization of a disease resistance response gene in pea inducible by Fusarium solani. Mol. Plant-Microbe Interact. 3:78-85.

Chiang, C. C., and Hadwiger, L. A. 1991. The Fusarium solani-induced expression of a pea gene family encoding high cysteine content proteins. Mol. Plant-Microbe Interact. 4:324-331.

Cook, D., Dreyer, D., Bonnet, D., Howell, M., Nony, E., and VandenBosch, K. 1995. Transient induction of a peroxidase gene in Medicago truncatula precedes infection by Rhizobium meliloti. Plant Cell 7:43-55.

Corpet, F. 1988. Multiple sequence alignment with hierarchical clustering. Nucleic Acids Res. 16:10881-10890.

Cutt, J. R., and Klessig, D. F. 1992. Genes involved in plant defense. Pages 20-243 in: Plant Gene Research Series. T. Boller and F. Meins, eds. Springer, Vienna.

de Billy, F., Barker, D., Gallusci, P., and Truchet, G. 1991. Leghaemoglobin gene transcription is triggered in a single cell layer in the indeterminate nitrogen-fixing root nodule of alfalfa. Plant J. 1:27-35. 
De Jong, A. J., Cordewener, J., Lo Schiavo, F., Terzi, M., Vandekerckove, J., Van Kammen, A., and De Vries, S. C. 1992. A carrot somatic embryo mutant is rescued by chitinase. Plant Cell 4:425-433.

Debellé, F., Rosenberg, C., Vasse, J., Maillet, F., Martinez, E., Dénarié, J., and Truchet, G. 1986. Assignment of symbiotic developmental phenotypes to common and specific (nod) genetic loci of Rhizobium meliloti. J. Bacteriol. 168:1075-1086.

Dénarié, J., Debellé, F., and Promé, J. C. 1996. Rhizobium lipochitooligosaccharide nodulation factors: Signaling molecules mediating recognition and morphogenesis. Annu. Rev. Biochem. 65:503-535.

Esnault, R., Buffard, D., Breda, C., Sallaud, C., El Turk, J., and Kondorosi, A. 1993. Pathological and molecular characterizations of alfalfa interactions with compatible and incompatible bacteria, Xanthomonas campestris pv. alfalfae and Pseudomonas syringae pv. pisi. Mol. Plant-Microbe Interact. 6:655-664.

Faucher, C., Camut, S., Dénarié, J., and Truchet, G. 1989. The nodH and nod $Q$ host range genes of Rhizobium meliloti behave as avirulence genes in R. leguminosarum bv. viciae and determine changes in the production of plant-specific extracellular signals. Mol. Plant-Microbe Interact. 2:291-300.

Florack, D. E. A., and Stiekema, W. J. 1994. Thionins: Properties, possible biological roles and mechanisms of action. Plant Mol. Biol. 26:25-37.

Gallusci, P., Dedieu, A., Journet, E. P., Huguet, T., and Barker, D. G. 1991. Synchronous expression of leghaemoglobin genes in Medicago truncatula during nitrogen-fixing root nodule development and response to exogenously supplied nitrate. Plant Mol. Biol. 17:335-349.

Gamas, P., de Carvalho Niebel, F., Lescure, N., and Cullimore, J. V. 1996. Use of a subtractive hybridization approach to identify new Medicago truncatula genes induced during root nodule development. Mol. Plant-Microbe Interact. 9:233-242.

Gu, Q., Kawata, E. E., Morse, M.-J., Wu, H.-M., and Cheung, A. 1992. A flower-specific cDNA encoding a novel thionin in tobacco. Mol. Gen. Genet. 234:89-96.

Hirsch, A. 1992. Developmental biology of legume nodulation. Tansley Review No. 40. New Phytol. 122:211-237.

Jackson, A. D., and Larkins, B. A. 1976. Influence of ionic strength, pH, and chelation of divalent metals on isolation of polyribosomes from tobacco leaves. Plant Physiol. 57:5-10.

Kado, C. I., and Heskett, M. G. 1970. Selective media for isolation of Agrobacterium, Corynebacterium, Erwinia, Pseudomonas, and Xanthomonas. Phytopathology 60:969-976.

Kijne, J. 1992. The Rhizobium infection process. Pages 348-397 in: Biological Nitrogen Fixation. G. Stacey, H. Evans, and R. Burris, eds. Chapman and Hall, London.

King, E. O., Ward, M. K., and Rancy, D. E. 1954. Two simple media for the demonstration of phycocyanin and fluorescin. J. Lab. Clin. Med. 44:301-307.

Kragh, K. M., Nielsen, J. E., Nielsen, K. K., Dreboldt, S., and Mikkelsen, J. D. 1995. Characterization and localization of new antifungal cysteine-rich proteins from Beta vulgaris. Mol. Plant-Microbe Interact. 8:424-434.

Kyte, J., and Doolittle, R. F. 1982. A simple method for displaying the hydropathic character of a protein. J. Mol. Biol. 157:105-132.

Löbler, M., and Hirsch, A. M. 1993. A gene that encodes a proline-rich nodulin with limited homology to PsENOD12 is expressed in the invasion zone of Rhizobium meliloti-induced alfalfa root nodules. Plant Physiol. 103:21-30.

Long, S. 1996. Rhizobium symbiosis: Nod factors in perspective. Plant Cell 8:1885-1898.

Lotan, T., Ori, N., and Fluhr, R. 1989. Pathogenesis-related proteins are developmentally regulated in tobacco flowers. Plant Cell 1:881-887.

McKhann, H. I., and Hirsch, A. M. 1994. Does Rhizobium avoid the host response? Pages 139-162 in: Bacterial Pathogenesis of Plants and Animals. J. L. Dangl, ed. Springer-Verlag, Berlin.

Milligan, S. B., and Gasser, C. S. 1995. Nature and regulation of pistilexpressed genes in tomato. Plant Mol. Biol. 28:691-711.

Moiseyev, G., Beintema, J., Fedoreyeva, L., and Yakovlev, G. 1994. High sequence similarity between a ribonuclease from ginseng calluses and fungus-elicited proteins from parsley indicates that intracellular pathogenesis-related proteins are ribonucleases. Planta 193: 470-472.

Mylona, P., Moerman, M., Yang, W.-C., Gloudemans, T., Vandekerckove, J., Van Kammen, A., Bisseling, T., and Franssen, H. J. 1994. The root epidermis-specific pea gene RH2 is homologous to a pathogenesis-related gene. Plant Mol. Biol. 26:39-50.

Nakai, K., and Kanehisa, M. 1992. A knowledge base for predicting protein localization sites in eukaryotic cells. Genomics 14:897-911.

Neale, A. D., Wahleithner, J. A., Lund, M., Bonnett, H. T., Kelly, A., Meeks-Wagner, D. R., Peacock, W. J., and Dennis, E. S. 1990. Chitinase, $\beta$-1,3-glucanase, osmotin, and extensin are expressed in tobacco explants during flower formation. Plant Cell 2:673-684.

Niehaus, K., Kapp, D., and Pühler, A. 1993. Plant defense and delayed infection of alfalfa pseudonodules induced by an exopolysaccharide (EPS I)-deficient Rhizobium meliloti mutant. Planta 190:415-425.

Noel, K. D., VandenBosch, K. A., and Kulpaca, B. 1986. Mutations in Rhizobium phaseoli that lead to arrested development of infection threads. J. Bacteriol. 168:1392-1401.

Pawlowski, K., and Bisseling, T. 1996. Rhizobial and actinorhizal symbioses: What are the shared features? Plant Cell 8:1899-1913.

Pichon, M., Journet, E. P., Dedieu, A., de Billy, F., Truchet, G., and Barker, D. G. 1992. Rhizobium meliloti elicits transient expression of the early nodulin gene ENOD12 in the differentiating root epidermis of transgenic alfalfa. Plant Cell 4:1199-1211.

Roche, P., Debellé, F., Maillet, F., Lerouge, P., Faucher, C., Truchet, G., Dénarié, J., and Promé, J. C. 1991. Molecular basis of symbiotic host specificity in Rhizobium meliloti: nodH and nodPQ genes encode the sulfation of lipo-oligosaccharide signals. Cell 67:1131-1143.

Sambrook, J., Fritsch, E. F., and Maniatis, T. A. 1989. Molecular Cloning: A Laboratory Manual. 2nd ed. Cold Spring Harbor Laboratory, Cold Spring Harbor, NY.

Scheres, B., Van Engelen, F., Van der Knaap, E., Van de Wiel, C., Van Kammen, A., and Bisseling, T. 1990. Sequential induction of nodulin gene expression in the developing pea nodule. Plant Cell 2:687-700.

Schultze, M., and Kondorosi, A. 1996. The role of lipooligosaccharides in root nodule organogenesis and plant cell growth. Curr. Opin. Genet. Devel. 6:631-638.

Spaink, H. P. 1996. Regulation of plant morphogenesis by lipo-chitin oligosaccharides. Crit. Rev. Plant Sci. 15:559-582.

Staehelin, C., Schultze, M., Kondorosi, E., Mellor, R. B., Boller, T., and Kondorosi, A. 1994. Structural modifications in Rhizobium meliloti Nod factors influence their stability against hydrolysis by root chitinases. Plant J. 5:319-330.

Swoboda, I., Hoffmann-Sommergruber, K., O'Riordain, G., Scheiner O., Heberle-Bors, E., and Vicente, O. 1996. Bet v 1 proteins, the major birch pollen allergens and members of conserved pathogenesisrelated proteins, show ribonuclease activity in vitro. Physiol. Plant. 96:433-438.

Swoboda, I., Scheiner, O., Heberle-Bors, E., and Vicente, O. 1995. cDNA cloning and characterization of three birch genes, members of the bet $\mathrm{v} 1$ gene family of pollen allergens, that encode pathogenesisrelated proteins. Plant Cell Environ. 18:865-874.

Truchet, G., Barker, D. G., Camut, S., de Billy, F., Vasse, J., and Huguet, T. 1989. Alfalfa nodulation in the absence of Rhizobium. Mol. Gen Genet. 219:65-68.

Truesdell, G., and Dickman, M. 1997. Isolation of pathogen/stressinducible cDNAs from alfalfa by mRNA differential display. Plant Mol. Biol. 33:737-743.

Van de Wiel, C., Norris, J., Bochenek, B., Dickstein, R., Bisseling, T., and Hirsch, A. 1990. Nodulin gene expression and ENOD2 localization in effective, nitrogen-fixing and ineffective, bacteria-free nodules of alfalfa. Plant Cell 2:1009-1017.

Van Kammen, A. 1984. Suggested nomenclature for plant genes involved in nodulation and symbiosis. Plant Mol. Biol. Rep. 2:43-45.

Van Loon, L. C., Pierpoint, W. S., Boller, T., and Conejero, V. 1994. Recommendations for naming plant pathogenesis-related proteins. Plant Mol. Biol. Rep. 12:245-264.

Vasse, J., de Billy, F., Camut, S., and Truchet, G. 1990. Correlation between ultrastructural differentiation of bacteroids and nitrogen fixation in alfalfa nodules. J. Bacteriol. 172:4295-4306.

Vasse, J., de Billy, F., and Truchet, G. 1993. Abortion of infection during the Rhizobium meliloti-alfalfa symbiotic interaction is accompanied by a hypersensitive reaction. Plant J. 4:555-566.

Wilson, R. C., Long, F., Maruoka, E. M., and Cooper, J. C. 1994. A new proline-rich early nodulin from Medicago truncatula is highly expressed in nodule meristematic cells. Plant Cell 6:1265-1275.

Yang, C., Signer, E. R., and Hirsch, A. M. 1992. Nodules initiated by Rhizobium meliloti exopolysaccharide mutants lack a discrete, persistent nodule meristem. Plant Physiol. 98:143-151. 